\title{
Conjugation of haloperidol to PEG allows peripheral localisation of haloperidol and eliminates CNS extrapyramidal effects
}

Article

Accepted Version

Creative Commons: Attribution-Noncommercial-No Derivative Works 4.0

Natfji, A. A., Nikitin, D. O., Semina, I. I., Moustafine, R. I., Khutoryanskiy, V. V., Lin, H., Stephens, G. J., Watson, K. A., Osborn, H. M. I. and Greco, F. (2020) Conjugation of haloperidol to PEG allows peripheral localisation of haloperidol and eliminates CNS extrapyramidal effects. Journal of Controlled Release, 322. pp. 227-235. ISSN 0168-3659 doi: https://doi.org/10.1016/j.jconrel.2020.02.037 Available at https://centaur.reading.ac.uk/90151/

It is advisable to refer to the publisher's version if you intend to cite from the work. See Guidance on citing.

To link to this article DOI: http://dx.doi.org/10.1016/j.jconrel.2020.02.037

Publisher: Elsevier

All outputs in CentAUR are protected by Intellectual Property Rights law, including copyright law. Copyright and IPR is retained by the creators or other copyright holders. Terms and conditions for use of this material are defined in the End User Agreement. 


\section{CentAUR}

Central Archive at the University of Reading

Reading's research outputs online 


\title{
Conjugation of haloperidol to PEG allows peripheral localisation of haloperidol and eliminates CNS extrapyramidal effects
}

\author{
Az Alddien Natfji ${ }^{a}$, Dmitry O. Nikitin ${ }^{b}$, Irina I. Semina ${ }^{b}$, Rouslan I. Moustafine ${ }^{c}$, Vitaliy \\ V. Khutoryanskiy ${ }^{\text {a,c }}$, Hong Lin ${ }^{a}$, Gary J. Stephens ${ }^{\text {a }}$, Kimberly A. Watson ${ }^{\text {, }}$, Helen M. I. \\ Osborn $^{a}$, Francesca Greco ${ }^{a}$, \\ a Reading School of Pharmacy, University of Reading, Whiteknights, Reading, RG6 6AD, \\ UK. \\ ${ }^{\mathrm{b}}$ Department of Pharmacology, Kazan State Medical University, 6/30 Tolstogo Street, \\ 420012 Kazan, Russian Federation \\ ${ }^{\mathrm{c}}$ Institute of Pharmacy, Kazan State Medical University, 16 Fatykh Amirkhan Street, 420126 \\ Kazan, Russian Federation \\ ${ }^{\mathrm{d}}$ Institute of Cardiovascular and Metabolic Research, School of Biological Sciences, \\ University of Reading, Whiteknights, RG6 6AS Berkshire, UK \\ ${ }^{*}$ Correspondence to: Francesca Greco (E-mail: f.greco@reading.ac.uk)
}

\begin{abstract}
We have previously reported the synthesis of a poly(ethylene glycol)-haloperidol (PEGhaloperidol) conjugate that retained affinity for its target $\mathrm{D}_{2}$ receptor and was stable in simulated physiological conditions. We hypothesised that this polymer-drug conjugate would localise haloperidol's activity either centrally or peripherally, dependent on the location of administration, due to the polymer preventing penetration through the blood-brain barrier (BBB). Herein, we validate this hypothesis using in vitro and in vivo studies. We first demonstrate, via a $\left[{ }^{35} \mathrm{~S}\right] \mathrm{GTP} \gamma \mathrm{S}$-binding assay, that drug activity is retained after conjugation to the polymer, supportive of retention of effective therapeutic ability. Specifically, the PEGhaloperidol conjugate (at 10 and $100 \mathrm{nM}$ ) was able to significantly inhibit dopamine-induced G-protein activation via $\mathrm{D}_{2}$ receptors, albeit with a loss of potency compared to the free haloperidol ( 18 -fold at $10 \mathrm{nM})$. This loss of potency was further probed and rationalised using molecular docking experiments, which indicated that conjugated haloperidol can still bind to the $\mathrm{D}_{2}$ receptors, albeit with a flipped orientation in the biding pocket within the receptor, which may explain the reduced activity. Finally, rat catalepsy studies confirmed the restricted permeation of the conjugate through the $\mathrm{BBB}$ in vivo. Rats treated intravenously with free haloperidol became cataleptic, whereas normal behaviour was observed in rats that received the PEG-haloperidol conjugate, suggesting that conjugation can effectively prevent unwanted central effects. Taken together these results demonstrate that conjugating small
\end{abstract}


molecules to polymers is effective at prohibiting penetration of the drug through the BBB and is a valid targeting strategy for drugs to facilitate peripheral (or central) effects without inducing side effects in other compartments.

\section{Keywords:}

Nanotechnology, nanomedicine, polymer-drug conjugate, blood-brain barrier, haloperidol, PEG. 


\section{Introduction}

Penetration through the blood-brain barrier (BBB) is recognised as a significant challenge when developing therapeutic agents for diseases of the central nervous system, for example, for psychiatric disorders and Alzheimer's disease [1]. What is less well articulated, however, is the requirement to prevent certain peripheral therapeutic drugs from crossing the BBB $[2,3]$. This need can be demonstrated by considering first-generation antihistamine agents where beneficial peripheral effects can be compromised by unwanted sedative effects when the drug crosses the BBB and acts centrally [4]. Since the size is a key parameter affecting permeability across the BBB, with 500 Da typically being considered as the maximum threshold for BBB permeability, one strategy to reduce penetration through the BBB is to form a polymer-drug conjugate (PDC) [5,6]. A very limited number of studies (three to the best of our knowledge) have previously demonstrated that PDCs can indeed restrict drug activity to peripheral organs and prevent undesired effects in the CNS. A PDC of an $N-(2-$ hydroxypropyl)methacrylamide (HPMA) copolymer and TNP-470, an anti-tumour agent, using a biologically labile tetrapeptide linker, significantly reduced TNP-470-related neurotoxicity in comparison to the free TNP-470 [7]. Movantik ${ }^{\circledR}$, a PDC in which naloxol (an opioid antagonist) is covalently linked to poly(ethylene glycol) (PEG) via a biologically stable ether linkage, has been used clinically to prevent opioid-induced constipation [8]. Third, and of particular relevance to the work presented here, we have reported the synthesis and characterisation of a non-prodrug PDC in which the $\mathrm{D}_{2}$ antagonist haloperidol was conjugated to PEG via a biologically stable carbamate linkage (Fig. 1) [9]. We demonstrated stability of the linker in vitro and presented evidence of potential activity by demonstrating that the PEG-haloperidol conjugate retains binding affinity (albeit reduced) to $\mathrm{D}_{2}$ receptors; we also showed initial evidence that PEG conjugation could prevent haloperidol crossing the BBB through a simple single in silico equation, based on methodology reported in Fu et al [10]. 

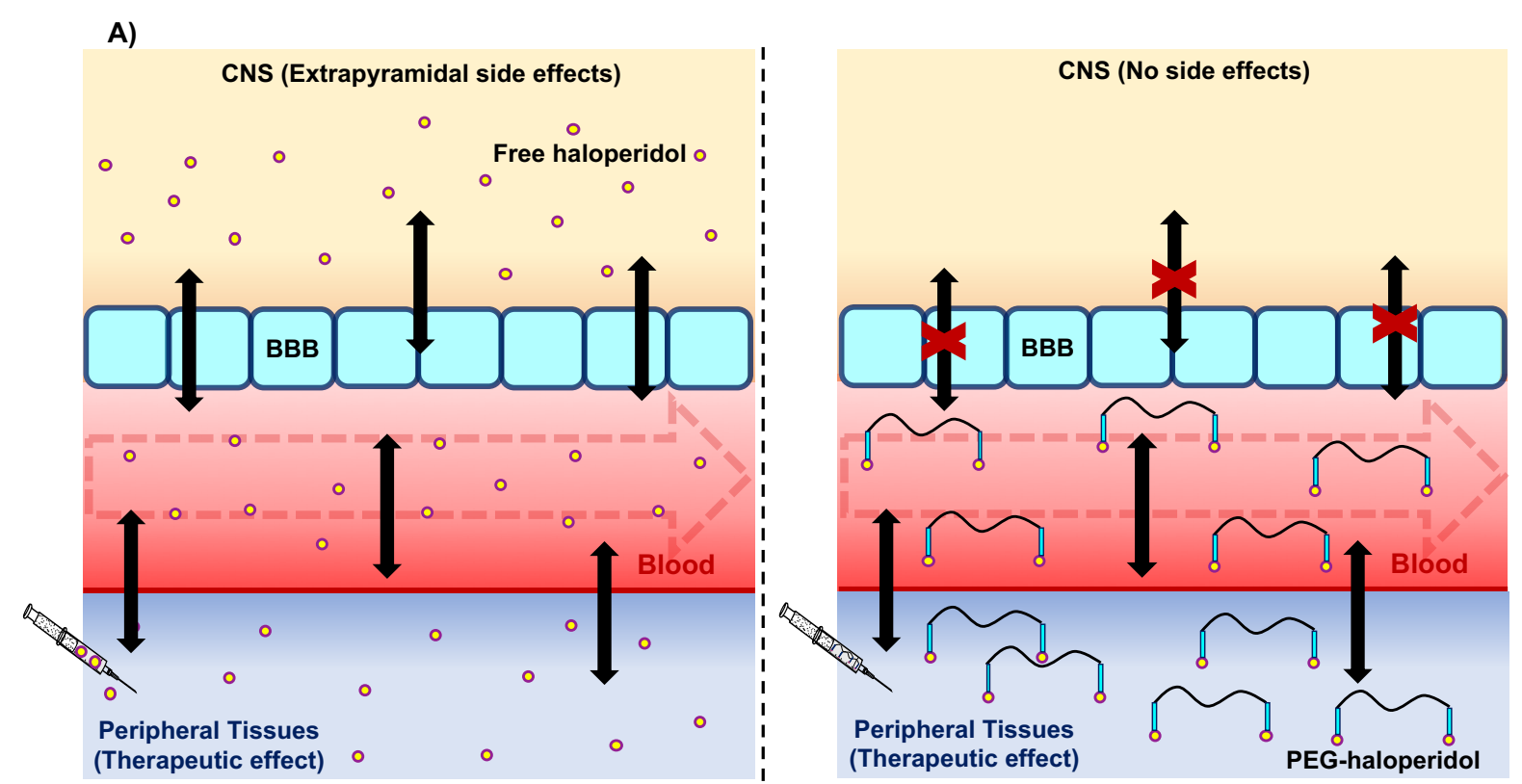

B) C)<smiles>O=C(CCCN1CCC(O)(c2ccc(Cl)cc2)CC1)c1ccc(F)cc1</smiles>

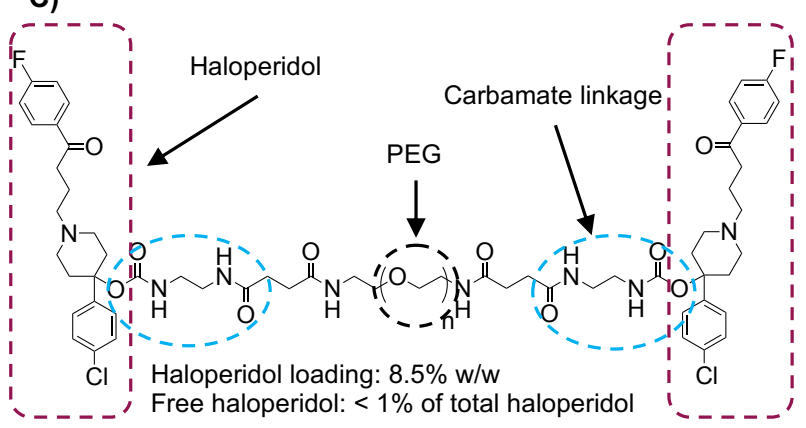

Fig. 1. Panel A, Distribution of free haloperidol in the central nervous system (CNS) and peripheral tissues after its peripheral administration and the ability of the conjugate to localise the effect of haloperidol peripherally; Panel B, Chemical structure of haloperidol; Panel C, Chemical structure and characterisation of PEG-haloperidol.

In the present study, and for the first time, we robustly demonstrate the feasibility of using PEG to prevent penetration of the haloperidol through the BBB using in vitro and in vivo approaches. Specifically, the pharmacological activity of the PEG-haloperidol conjugate was assessed in vitro by measuring the inhibition of dopamine-induced $\left[{ }^{35} \mathrm{~S}\right] \mathrm{GTP} \gamma \mathrm{S}-$-binding via $\mathrm{D}_{2}$ receptors. Next, we interpret the retained biological potency of conjugated haloperidol by looking at the effect of PEGylation on haloperidol binding to $\mathrm{D}_{2}$ receptors using in silico molecular docking studies. Finally, and of particular significance, we extended our study and evaluated the penetration of peripherally administered PEG-haloperidol conjugate through the BBB in vivo. This was carried out by recording catalepsy in rats, as an indication of haloperidol-induced CNS extrapyramidal side effects.

We demonstrate that the PEG conjugation strategy used was capable of preventing the penetration of conjugated haloperidol through the $\mathrm{BBB}$ and propose that such strategies can prevent unwanted central side effects of peripherally administered drugs (and/or vice versa), 
and would form a strong base to re-direct the use of haloperidol, and similar drugs, to treat peripheral non-CNS diseases such as cardiovascular diseases and cancers.

\section{Materials and methods}

\subsection{Materials}

Alpha,omega-di-succinimidyl ester poly(ethylene glycol) (MW 6,429 Da) was obtained from Iris Biotech GmbH, Germany. Haloperidol was purchased from Sigma-Aldrich (UK). The radioligand $\left[{ }^{35} \mathrm{~S}\right] \mathrm{GTP} \gamma \mathrm{S}$ was purchased from PerkinElmer (UK). All other chemicals and solvents were purchased from Fisher Scientific (UK) and Sigma-Aldrich (UK), respectively and utilised without any further purification unless otherwise stated.

\subsection{The synthesis and characterisation of PEG-haloperidol}

PEGylation of haloperidol was carried out as described previously with minor modifications [9]: anhydrous DMF was replaced with anhydrous THF, and NHS-PEG-NHS was purchased rather than activating PEG-COOH in house. Further details are provided in the Supporting Information.

\subsection{In vitro assessment of the biological activity}

\section{Cell culture}

CHO expressing dopamine $\mathrm{D}_{2}$ receptors were cultured in Dulbecco's modified Eagle's medium (high glucose, supplemented with 1\% L-glutamine; Sigma-Aldrich, UK), 5\% fetal bovine serum $\left(\mathrm{Gibco}^{\mathrm{TM}}\right.$, UK), 1\% non-essential amino acids (Gibco $\left.{ }^{\mathrm{TM}}, \mathrm{UK}\right)$. To maintain selection pressure, $500 \mu \mathrm{g} / \mathrm{mL}$ of geneticin $\left(\mathrm{Gibco}^{\mathrm{TM}}\right.$, UK) was added to the growth medium. The cells were incubated in a humidified atmosphere with $5 \% \mathrm{CO}_{2}$ at $37^{\circ} \mathrm{C}$.

\section{Cell membrane preparation}

Cell membranes from $\mathrm{CHO}$ cells stably expressing the dopamine $\mathrm{D}_{2}$ receptors were prepared as previously described in [11]. Briefly, confluent cells in $175 \mathrm{~cm}^{2}$ flasks were washed twice with 5 mL HEPES buffer (20 mM HEPES, 1 mM EDTA, and 1 mM EGTA; pH 7.4). Cells were then detached from the flask surface using glass beads and $\sim 8 \mathrm{~mL}$ of HEPES buffer. The collected cells were homogenised using an Ultra-Turax homogeniser $(4 \times 10$ second run). The homogenate was centrifuged at $1000 \mathrm{~g}$ for $10 \mathrm{~min}$ at $4{ }^{\circ} \mathrm{C}$. The supernatant was then 
centrifuged at $39000 \mathrm{~g}$ for $1 \mathrm{~h}$ at $4{ }^{\circ} \mathrm{C}$. Next, the pellet was resuspended in HEPES buffer and stored as aliquots at $-80{ }^{\circ} \mathrm{C}$. The amount of protein $\left(\mathrm{D}_{2}\right.$ receptor) was determined using Lowry et al method [12]. Further details are provided in the Supporting Information.

\section{$\left[{ }^{35} S\right] G T P \gamma S$-binding assay}

Cell membrane $(20 \mu \mathrm{g})$ was incubated with dopamine (a $\mathrm{D}_{2}$ receptor agonist) at a range of concentrations $1 \mathrm{nM}$ to $10 \mathrm{mM}$ either alone or with: a) the $\mathrm{D}_{2}$ receptor antagonist haloperidol; b) PEG-haloperidol; or c) PEG-COOH (6,000 Da) (negative control) at two concentrations (Table 1) in $900 \mu \mathrm{L}$ HEPES buffer (20 mM HEPES, $60 \mathrm{mM} \mathrm{NaCl}, 3 \mathrm{mM} \mathrm{MgCl}{ }_{2}$ and $1 \mathrm{mM}$ EGTA, $0.5 \mathrm{mg} / \mathrm{mL}$ fatty acid - free BSA; pH 7.4) supplemented with $(100 \mu \mathrm{M})$ dithiothreitol and $(10 \mu \mathrm{M}) \mathrm{GDP}$ for $30 \mathrm{~min}$ at $30^{\circ} \mathrm{C}$.

Table 1. Drugs and their concentrations used in the $\left[{ }^{35} \mathrm{~S}\right] \mathrm{GTP} \gamma \mathrm{S}$-binding.

\begin{tabular}{ll}
\hline Drugs & Tested concentrations \\
\hline Dopamine & $1 \mathrm{nM}-10 \mathrm{mM}$ \\
\hline Dopamine + Haloperidol & $1 \mathrm{nM}-10 \mathrm{mM}$ of dopamine $+10 \mathrm{nM}$ or 100 $\mathrm{nM}$ of haloperidol \\
\hline Dopamine + PEG-haloperidol & $\begin{array}{l}1 \mathrm{nM}-10 \mathrm{mM} \text { of dopamine }+10 \mathrm{nM} \text { and } 100 \mathrm{nM} \text { of PEG-haloperidol } \\
\text { (haloperidol equivalent) }\end{array}$ \\
\hline Dopamine + PEG-COOH & $\begin{array}{l}1 \mathrm{nM}-10 \mathrm{mM} \text { of dopamine }+10 \mathrm{nM} \text { and 100 nM of PEG-COOH } \\
\text { (haloperidol equivalent) }\end{array}$ \\
\hline
\end{tabular}

To initiate the reaction, $\left[{ }^{35} \mathrm{~S}\right] \mathrm{GTP} \gamma \mathrm{S}(100 \mu \mathrm{L})$ was added to give a final concentration of 100 $\mathrm{pM}\left[{ }^{35} \mathrm{~S}\right] \mathrm{GTP} \gamma \mathrm{S}$. The reaction mixture was further incubated for $30 \mathrm{~min}$ at $30{ }^{\circ} \mathrm{C}$. The reaction was then terminated by rapid filtration through Whatman filters $(\mathrm{GF} / \mathrm{C})$, using a Brandel cell harvester, followed by 4 cycles of wash with ice-cold PBS ( $\sim 4 \mathrm{~mL}, 5 \mathrm{mM}$ $\mathrm{Na}_{2} \mathrm{HPO}_{4}, 1.5 \mathrm{mM} \mathrm{KH}_{2} \mathrm{PO}_{4}, 3 \mathrm{mM} \mathrm{KCl}, 0.14 \mathrm{M} \mathrm{NaCl} ; \mathrm{pH} 7.4$ ) to remove unbound $\left.{ }^{35} \mathrm{~S}\right] \mathrm{GTP} \gamma \mathrm{S}$. The filters were soaked in $2 \mathrm{~mL}$ of scintillation fluid overnight and the bound radioactivity $\left(\left[{ }^{35} \mathrm{~S}\right] \mathrm{GTP} \gamma \mathrm{S}\right)$ was determined via liquid scintillation counting. All data were performed in triplicate. $\mathrm{pEC}_{50}$ values were determined, using GraphPad Prism (v5.04) software.

\subsection{Molecular Docking}

Molecular docking studies were performed using the programme Surflex-Dock (SFXC) [13], as provided by Sybyl-X 2.1. The X-ray crystallographic structure of human $\mathrm{D}_{2}$ receptor complexed with risperidone (an antagonist) was retrieved from the Protein Data Bank (PDBid 6CM4, $2.87 \AA$ resolution) [14]. The protein structure was prepared for docking, using the Biopolymer Structure Preparation Tool, with the implemented default settings provided in 
the SYBYL programme suite. The 3D structures of haloperidol and PEG-haloperidol (1 to 5 ethylene oxide monomers) were drawn using ChemDraw Professional 16, MarvinSketch 18.8.0 and Maestro program [15]. Preparation of the ligands was carried out using the Ligand Preparation tool in Sybyl-2.1. Further details of the docking procedure can be found in the Supporting Information. The docking results were visualised using the programme PyMOL and MAESTRO [15-17] and the molecular interactions of the docked ligands were analysed using the programme MAESTRO. Potential hydrogen bonds were assigned if the distance between two electronegative atoms was less than $3.3 \AA$, whereas any separation greater than $3.3 \AA$, but less than $4.5 \AA$, was considered a van der Waal interaction. Further details are provided in the Supporting Information.

\subsection{In vivo catalepsy recording test}

\section{Animals}

10 Female and male Wistar rats weighing (mean weight $315 \mathrm{~g}$ ) were used in this study. All animals were kept in standard vivarium conditions with a natural light-dark cycle, and they were allowed to access a full-balanced diet. All usage of the animals and the experimental procedures were in compliance with the International Recommendations of the European Convention for the Protection of Vertebrates, and the rules of laboratory practice for carrying out preclinical research in the Russian Federation (GOST G 51000.3-96 and 51000.4-96). All studies were approved by the ethical review committee (approval no. 10 from $19^{\text {th }}$ December 2017).

\section{Catalepsy test}

In this test, the front paws of the animal were gently placed on a horizontal plastic bar located at a height of $10 \mathrm{~cm}$ in a wooden box. The time the animal spent in maintaining this abnormal posture was recorded. A commercial formulation of haloperidol was used as received (5 $\mathrm{mg} / \mathrm{mL}$ haloperidol sterile solutions containing lactic acid, Ozone Pharmaceutica Ltd, Russian Federation); PEG-haloperidol was dissolved in sterile water. All drugs were administered intravenously at a dose of $1 \mathrm{mg} / \mathrm{kg}$ (haloperidol equivalent) via the tail vein (mixed male and female rats, 5 rats/group). The animals were placed on the bar at different time intervals for 3 hours after the administration. A scoring system (from 1 to 6 ) was used to rate the time the rat spent on the bar $(0-10 \mathrm{~s}=1,11-20 \mathrm{~s}=2,21-30 \mathrm{~s}=3,31-40 \mathrm{~s}=4,41-50$ $s=5$ or $51-60 s$ or more $=6$ ). A score of at least 3 was used as a cut-off score of catalepsy [18]. 


\subsection{Statistical analysis}

Data are presented as mean \pm s.e.m (standard error of mean, $n=3$ unless otherwise stated). Statistical significance was predicted using the unpaired Student's t-test or one-way ANOVA (Analysis of Variance) test prior to Bonferroni's post hoc test. Statistical significance $(*: p<$ $0.05, * * *: \mathrm{p}<0.001, \mathrm{~ns}$ : not significant) was set in the parameters.

\section{Results and Discussion}

This work studied the impact of conjugating haloperidol to PEG through a biologically stable linker on the biological activity of haloperidol and its ability to penetrate the BBB.

Bifunctional conjugation of PEG was chosen to balance the need for appropriate drug loading of haloperidol $(\mathrm{w} / \mathrm{w})$ with using an appropriate PEG chain length that would prevent penetration of the conjugated haloperidol through the BBB whilst also producing a clinically relevant half-life. The average haloperidol content in the conjugate, as determined via ${ }^{1} \mathrm{H}$ NMR spectroscopic analysis, is $8.5 \% \mathrm{w} / \mathrm{w}$ and that is equivalent to an average (1.6) haloperidol molecules per PEG chain. Biological activity was assessed in vitro by assaying inhibition of dopamine-mediated $\mathrm{G}$ protein turnover via $\mathrm{D}_{2}$ receptors by PEG-haloperidol as a non-prodrug system. This was followed by in silico molecular docking studies to understand the consequence of conjugation on the biological activity of haloperidol. The restricted penetration of PEGylated haloperidol through the BBB was confirmed by recording catalepsy in rats.

\subsection{PEG-haloperidol inhibition of dopamine-induced activity in $\mathrm{D}_{2}$ receptors}

In order for the PDC to be effective as a non-prodrug therapeutic agent, it is essential that it retains biological activity at the target of the free drug. Since our PDC contained haloperidol, we sought to determine the ability of PEG-haloperidol to inhibit dopamine-induced G protein activation as an indication of its retained biological activity on $\mathrm{D}_{2}$ receptors. We have previously demonstrated that PEG-haloperidol can bind to the $\mathrm{D}_{2}$ receptors in the system used [9]. Here, we investigated the effects of PEGylation of haloperidol on its ability to modulate agonist-induced $\mathrm{G}$ protein turnover via $\mathrm{D}_{2}$ dopamine receptors using the well-established $\left[{ }^{35} \mathrm{~S}\right] \mathrm{GTP} \gamma \mathrm{S}$-binding assay. Dopamine was used as a control that exhibits full agonist stimulation, whereas free haloperidol and PEG were used as a positive and negative control, respectively. The ligands (haloperidol and PEG-haloperidol) were tested at 10 and $100 \mathrm{nM}$, based on our previous findings [9]. Indeed, dopamine alone was able to induce $\mathrm{G}$ protein 
activation $\left(\mathrm{EC}_{50}=0.26 \mu \mathrm{M}\right.$, Table 2, Fig. 2), in agreement with the literature [19]. As expected, the addition of free haloperidol was able to significantly inhibit dopamine-induced stimulation of $\left[{ }^{35} \mathrm{~S}\right] \mathrm{GTP} \gamma \mathrm{S}$-binding (dopamine $\mathrm{EC}_{50}$ increased to 11.5 and $91.8 \mu \mathrm{M}$, in the presence of haloperidol at 10 and $100 \mathrm{nM}$, respectively, Table 2, Fig. 2).

Table 2. Inhibition of dopamine-stimulated $\left[{ }^{35} \mathrm{~S}\right] \mathrm{GTP} \gamma \mathrm{S}$-binding by haloperidol, PEG-haloperidol, and PEG. Values are expressed as Mean $\pm \operatorname{SEM}(\mathrm{n}=3)$.

\begin{tabular}{lcc}
\hline \multicolumn{1}{c}{ Drug } & pEC50 & EC $\mathbf{5 0}(\boldsymbol{\mu M})$ \\
\hline Dopamine & $6.59 \pm 0.07$ & 0.26 \\
\hline Dopamine + haloperidol 10 nM & $4.94 \pm 0.04 * * *$ & 11.5 \\
\hline Dopamine + haloperidol 100 nM & $4.05 \pm 0.09^{* * *}$ & 91.8 \\
\hline Dopamine + PEG-haloperidol 10 nM (haloperidol equivalent) & $6.19 \pm 0.02^{*}$ & 0.65 \\
\hline Dopamine + PEG-haloperidol 100 nM (haloperidol equivalent) & $5.81 \pm 0.11^{* * *}$ & 1.64 \\
\hline $\begin{array}{l}\text { Dopamine + PEG (control for the conjugate with 10 nM, } \\
\text { haloperidol equivalent) }+\end{array}$ & $6.52 \pm 0.06^{\mathrm{ns}}$ & 0.3 \\
\hline Dopamine + PEG (control for the conjugate with 100 nM, & $6.39 \pm 0.09^{\mathrm{ns}}$ & 0.43 \\
haloperidol equivalent) + & & \\
\hline
\end{tabular}

$\$$ no haloperidol present in the PEG controls, and the concentration of PEG in the PEG controls was identical to the concentration of PEG in the conjugate which the PEG acted as control for.

Interestingly, PEG-haloperidol retained biological activity with significant inhibition of the dopamine-induced stimulation of $\left[{ }^{35} \mathrm{~S}\right] \mathrm{GTP} \gamma \mathrm{S}$-binding at 10 and $100 \mathrm{nM}$ (haloperidol equivalent). However, dopamine $\mathrm{EC}_{50}(0.26 \mu \mathrm{M})$ was left-shifted relative to that of free haloperidol in the presence of 10 and $100 \mathrm{nM}$ conjugated haloperidol (haloperidol equivalent) to 0.65 and $1.64 \mu \mathrm{M}$, respectively (Table 2, Fig. 2).

However, the conjugated haloperidol increased dopamine $\mathrm{EC}_{50}(0.26 \mu \mathrm{M})$ more modestly than the free drug with $\mathrm{EC}_{50}$ of $0.65 \mathrm{vs} 11.5 \mu \mathrm{M}$ at a concentration of $10 \mathrm{nM}$ (haloperidol equivalent) and 1.64 vs $91.8 \mu \mathrm{M}$ at $100 \mathrm{nM}$ (haloperidol equivalent) (Table 2, Fig. 2). Thus, both PEGylated and free haloperidol could inhibit the dopamine-stimulated G protein activation, as the log concentration-response curves for dopamine were shifted to the right in a progressive manner by increasing concentrations of haloperidol and PEG-haloperidol, which were both significantly different from dopamine $(P<0.05)$. However, the potency of the conjugated haloperidol was weaker than that of free haloperidol ( $\sim 18$ fold at $10 \mathrm{nM}$ and $\sim 56$ fold at $100 \mathrm{nM}$ ), these values are in line with our previous binding study [9]. 

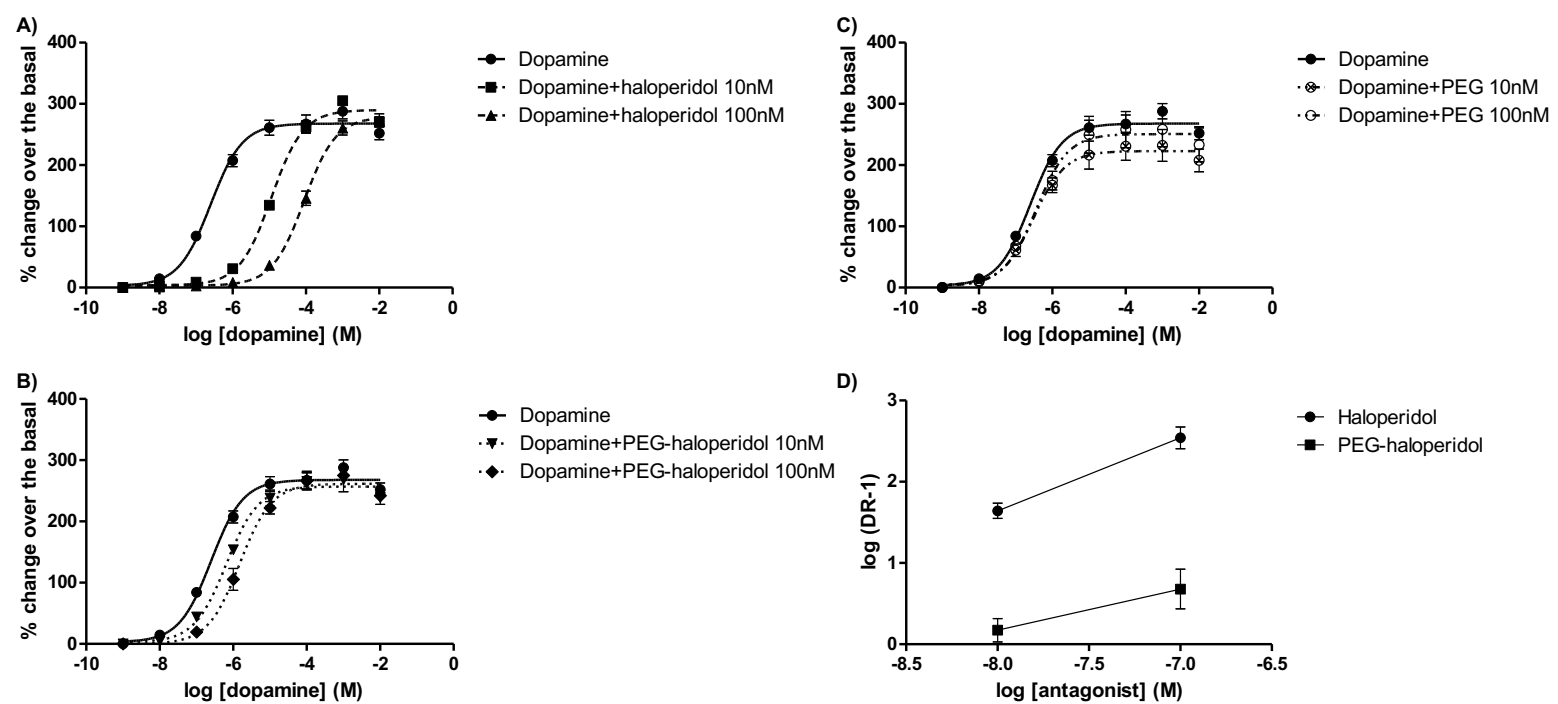

Fig. 2. Effects of haloperidol, PEG-haloperidol and PEG on dopamine stimulation of $\left[{ }^{35} \mathrm{~S}\right] \mathrm{GTP} \gamma \mathrm{S}$ binding. Dopamine stimulation of $\left[{ }^{35} \mathrm{~S}\right] \mathrm{GTP} \gamma \mathrm{S}$ binding to $\mathrm{D}_{2}$ receptors was assessed in the presence of two concentrations of tested compounds (10 and $100 \mathrm{nM}$, haloperidol equivalent). Panels A, B and C, Dopamine log concentration-response curves in the presence of haloperidol, PEG-haloperidol and PEG, respectively. Panel D, Estimates of haloperidol and PEG-haloperidol effects using dose-ratios. Data are presented as Mean \pm SEM, $n=3$.

Inhibitory effects of free and conjugated haloperidol on $\left[{ }^{35} \mathrm{~S}\right] \mathrm{GTP} \gamma \mathrm{S}-$ binding assay can also be visualised using dose-ratio data derived from the same log concentration-response curves (Fig. 2. D). Based on the two concentrations, it was confirmed that PEGylated haloperidol was less effective at inducing a response than free haloperidol, and at $100 \mathrm{nM}$, PEGylated haloperidol had more pronounced effects than at $10 \mathrm{nM}$. Of potential interest was that slopes generated by this analysis can be estimated to 0.90 for free haloperidol vs 0.50 for PEGylated haloperidol. These data are consistent with the hypothesis that the conjugated haloperidol may behave differently from free haloperidol (whose action is consistent with competitive antagonism), in that PEGylated haloperidol may act non-competitively.

These data are likely to be related to the lower affinity of PEG-haloperidol for the $\mathrm{D}_{2}$ receptors, due to conjugation (as further explored in section 3.2) and due to the reduced dynamic equilibrium during the experiment [20]. This condition might be related to the low diffusion rate and reduced uptake of conjugated haloperidol compared to the free haloperidol by $\mathrm{D}_{2}$ receptors of the isolated membrane due to conjugation to a large molecule.

Importantly, free PEG had no significant effect on dopamine-induced $\mathrm{G}$ protein turnover $(P$ $>0.05$ ), which indicated that the inhibition induced by PEG-haloperidol was related to the effects of haloperidol moiety on $\mathrm{D}_{2}$ receptors.

Given the loss in potency of the conjugate compared to free haloperidol and the administration as a conjugate rather than a free drug, one might conclude that the conjugate would need to be administered at a significantly higher (and, arguably, not practical) dose 
than the free drug. In fact, other factors are expected to counterbalance the need for an increased dose, namely: (a) increased bioavailability from administering the conjugate i.v. $(100 \%)$ compared to oral administration of haloperidol (60\%) [21]; (b) expected decrease in plasma protein binding compared to free haloperidol, which is heavily bound to plasma proteins (only $\sim 8 \%$ of total haloperidol in serum is available as the free form in the blood $[22,23])$; (c) if required, loading can be further increased by decreasing PEG's molecular weight. Taking (a) (b) and (c) together, we are estimating that the dose required, will be practically feasible.

\subsection{Molecular Docking}

In light of the in vitro $\left[{ }^{35} \mathrm{~S}\right] \mathrm{GTP} \gamma \mathrm{S}$-binding assay and our previous study of $\mathrm{D}_{2}$ receptor affinity binding of haloperidol and PEG-haloperidol [9], we conducted a molecular docking study in order to understand the impact, at a molecular level, of conjugating haloperidol to a polymer on its binding to $\mathrm{D}_{2}$ receptors.

First, we investigated the interactions of free haloperidol with $\mathrm{D}_{2}$ receptors. Haloperidol (Fig. 3) was docked sequentially into the binding sites, retrieved from [24], the X-ray crystallographic structure of human $\mathrm{D}_{2}$ receptor complexed with risperidone (PDB code $6 \mathrm{~cm} 4,2.87 \AA$ Å resolution) [14], using a previously validated docking procedure.

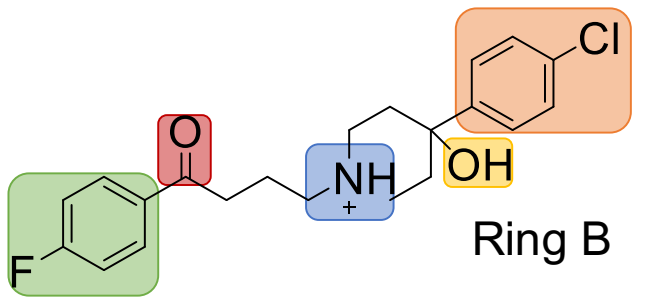

Ring A

Fig. 3. The chemical structure of haloperidol at $\mathrm{pH} 7.4$ representing different ring structures and functional groups. The results showed that the space occupied by haloperidol was in agreement with data previously reported for haloperidol interacting with a homology model developed for $\mathrm{D}_{2}$ receptors [24-27] (Fig. 4A, I). A $3.0 \AA$ salt bridge interaction was formed between the protonated nitrogen of the piperidine in haloperidol and Asp 114 (TM3 of the $\mathrm{D}_{2}$ receptor). In addition, a $3.4 \AA$ hydrogen bond was established with Ser 197 on TM5. While distant to what has been previously reported [24], ring A of haloperidol formed complementary heteroatom interactions with Trp 386 and Phe 390 at $4.9 \AA$ and $5.3 \AA$, respectively. Moreover, our results showed that the carbonyl group of the butyrophenone fragment was involved in a hydrogen bond with Cys 118 (TM3) at $3.2 \AA$ (Fig. 4A, II). Both ring B and the 
hydroxyl group of haloperidol (which is axial) were solvent accessible (Fig. 4A, III). Ring A was buried in the pocket and parallel to Trp 386 (TM6), while its fluorine atom was directed to Ile 128 (TM3) (Fig. 4A, IV). It is important to highlight that we found the molecular orientation of haloperidol within the $\mathrm{D}_{2}$ receptor to be different from the previously reported docking studies of haloperidol with a $180^{\circ}$ rotation of predicted orientations [24-26].

However, our results are in line with recently published data predicting the binding pathways of haloperidol in $\mathrm{D}_{2}$ receptors [27]. 
A)

I)

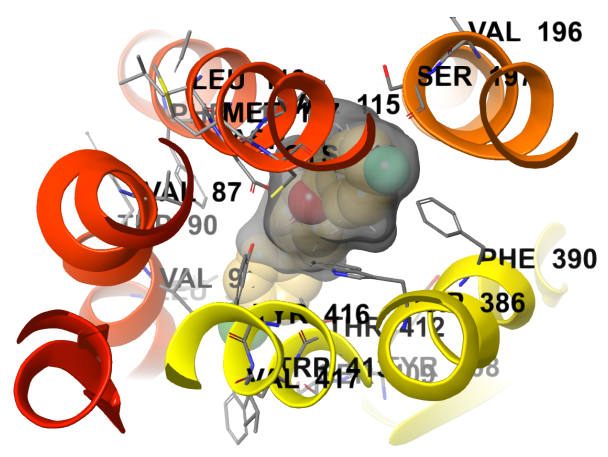

III)

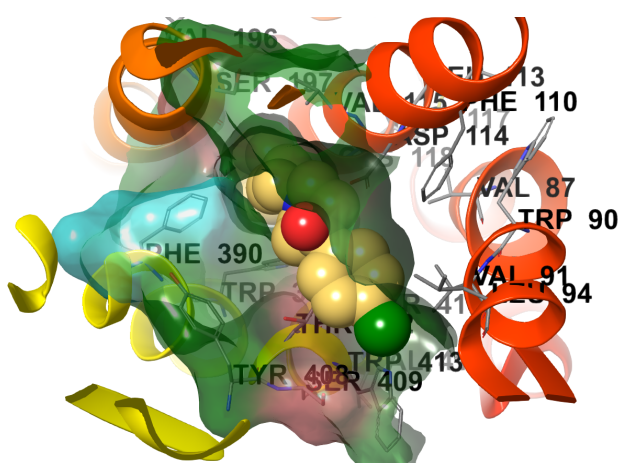

B)

I)

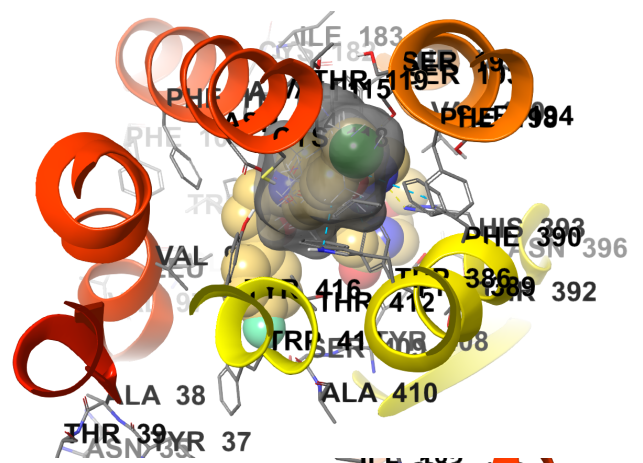

III)

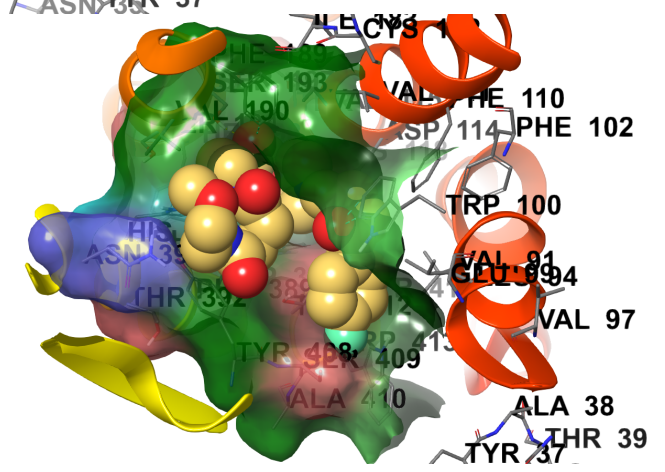

II)
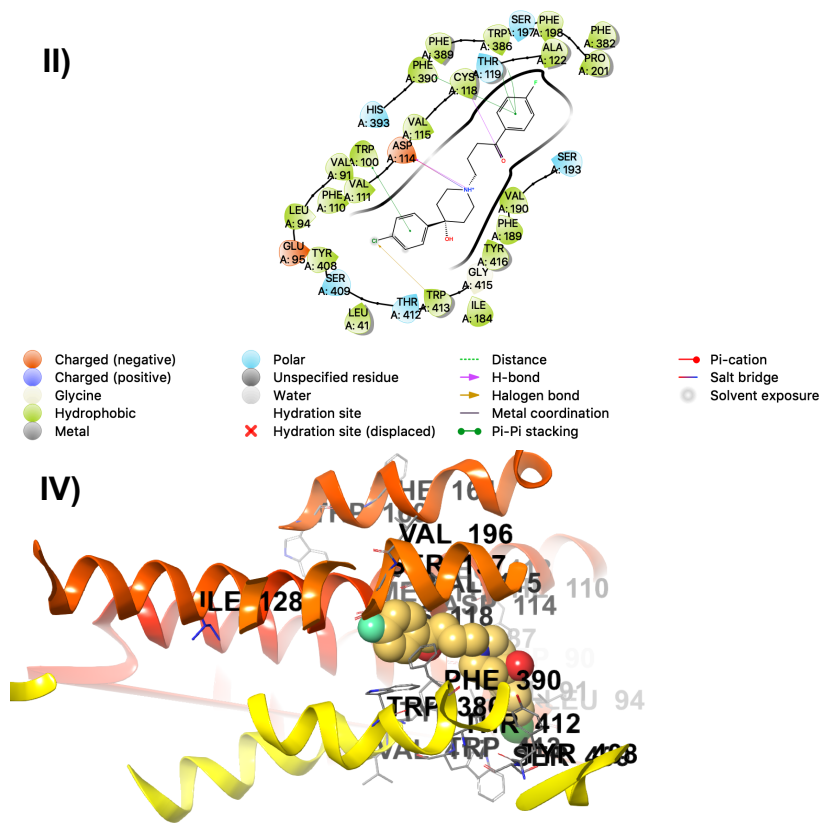

II)
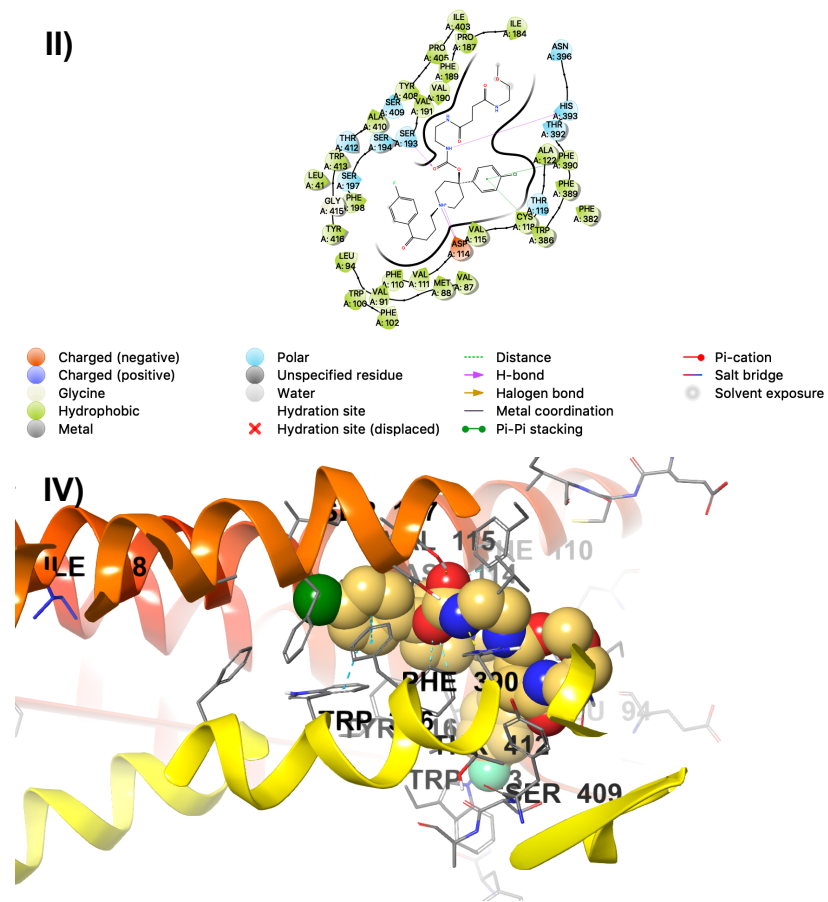

Fig. 4. Panel $\mathbf{A}$, a cartoon representation of haloperidol docking in $\mathrm{D}_{2}$ receptors. Panel $\mathbf{B}$, a cartoon representation of $\mathrm{PEG-}$ haloperidol docked into the $\mathrm{D}_{2}$ receptor. (I) data of the ligand in the binding pocket of $\mathrm{D}_{2}$ receptors; (II) detailed ligand- $\mathrm{D}_{2}$ receptor interactions; (III) solvent accessibility of the hydroxyl group and ring B in the case of free haloperidol or solvent accessible positions of ring A and the carbonyl group in the case of PEG-haloperidol; (IV) alignment of ring A and its fluorine of free haloperidol or alignment of ring B of and its chlorine of PEG-haloperidol.

In an attempt to mimic the binding of PEG-haloperidol conjugate to the $\mathrm{D}_{2}$ receptor, five $3 \mathrm{D}$ structures of PEG-haloperidol conjugates were prepared using ethylene oxide monomers in the PEG chain, ranging from 1 to 5 monomers. The data presented herein represents a PEG- 
haloperidol 3D structure with 1 ethylene oxide monomer, which provides an indication of the possible poses of longer conjugated haloperidol molecules within the $\mathrm{D}_{2}$ receptor. The remaining 4 conjugate haloperidol structures provided similar results to the monomeric conjugate (data not shown). The molecular docking studies of PEG-haloperidol conjugates revealed that the salt bridge between the protonated nitrogen of the piperidine ring in conjugated haloperidol and Asp 114 (TM3), which is essential for the biological activity, was preserved at $2.6 \AA$, however, the poses of conjugated haloperidol were flipped in the binding pocket compared to free haloperidol. Ring A and the carbonyl group both became solvent accessible and these were not involved in any significant interactions (Fig. 4B, I-III). However, as observed for the docked free haloperidol, ring B of conjugated haloperidol formed heteroatom interactions with Trp 386 and Phe 390 at $4.8 \AA$ and $5.1 \AA$, respectively (Fig. 4B, II). Ring B was buried in the pocket facing Ile 128 (TM3), instead of ring A observed for free haloperidol (Fig. 4B, IV).

These findings may provide possible explanations for the retained but reduced biological potency of PEGylated haloperidol in vitro. The retained biological activity for conjugated haloperidol might be directly related to the salt bridge interaction with a key Asp 114 residue, which both free and conjugated haloperidol are able to exploit. This aspartate residue plays an important role in specific binding of ligands to $G$ protein-coupled receptors, and mutations, typically to alanine, result in a loss of ligand binding to the receptors $[28,29]$. On the other hand, the change in space occupied by haloperidol after its conjugation could account for the reduction in activity (Fig. 5)

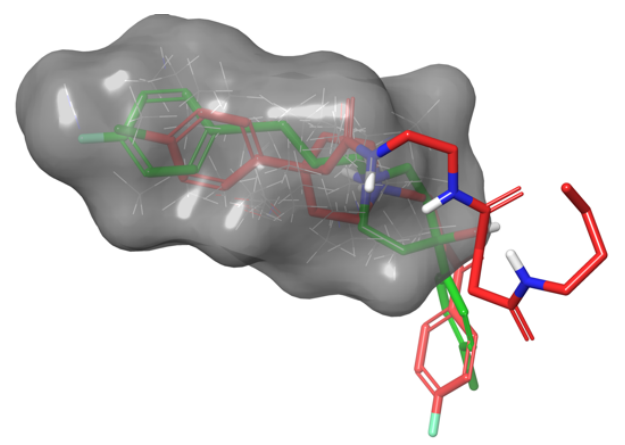

Fig. 5. Overlaid docked poses for haloperidol (in green) and PEG-haloperidol (in red) in the binding pocket.

The conjugation of haloperidol to PEG apparently results in a flipped orientation in the binding mode, making ring A and the carbonyl group (a butyrophenone moiety) solventaccessible rather than binding deep into the pocket of the $\mathrm{D}_{2}$ receptor. These results are in agreement with other experimental studies, which support the observation that the 
butyrophenone moiety must bind deep into the binding pocket in order to retain binding affinity towards $\mathrm{D}_{2}$ receptors [30,31]. Furthermore, the involvement of the hydroxyl group of haloperidol in the conjugation to PEG might be another reason for the reduced affinity and activity of PEG-haloperidol compared to free haloperidol. Different studies have reported that the presence of a hydroxyl group in the haloperidol structure at a position bound to the piperidine ring is not essential for haloperidol to bind to $\mathrm{D}_{2}$ receptors, however, its presence significantly increases affinity towards these receptors [32-34].

Although the PEG-haloperidol conjugate contains two haloperidol moieties, it is anticipated that, similarly to the unconjugated form, only one haloperidol will bind to the receptor due to the architectural restrictions in the binding site. It is possible that the other haloperidol could independently and simultaneously bind to a different $\mathrm{D}_{2}$ receptor nearby, but this is likely to be disfavoured from entropy considerations.

\subsection{Prevention of permeability, in vivo catalepsy recording test}

As a preliminary screen to determine the enthalpic impact of conjugation on permeability across the $\mathrm{BBB}$, theoretical calculations were carried out using literature-retrieved equations to predict $\log \mathrm{BB}$ values for both haloperidol and the conjugate. These demonstrated that, as per our design, in all cases, PEG-haloperidol was dramatically less permeable than the free haloperidol (Fig. S1, Fig. S2, Table S3, Table S4) (Supporting Information). However, it should be noted that these models do not account for entropic factors (which would also disfavour permeability across the BBB) and for pathways alternative to passive diffusion (which could potentially determine some permeability across the BBB). Therefore, to robustly test our hypothesis that polymer conjugation can be used to prevent permeability across the $\mathrm{BBB}$, the conjugate was evaluated in vivo. Therefore, the cataleptogenic effects of PEG-haloperidol were monitored in rats. Neuroleptic drugs (typical antipsychotics such as haloperidol) are well-known to induce catalepsy via inhibitory effects on the nigrostriatal dopamine system [35]. In addition, cataleptic symptoms in animals are used to predict the unwanted extrapyramidal side effects induced by antipsychotics due to their permeation through the BBB [36].

With the aim of assessing the penetration of free or conjugated haloperidol through the BBB, catalepsy was recorded in rats, at different time intervals, after the peripheral administration of the drug. Cataleptic responses were readily apparent in animals treated with haloperidol. The cataleptic effects of haloperidol commenced after 5 min of administration and lasted for at least $180 \mathrm{~min}$ (the duration of the test) (Fig. A). 
A)

$\mathrm{n}=5$, i.v. administration of free haloperidol

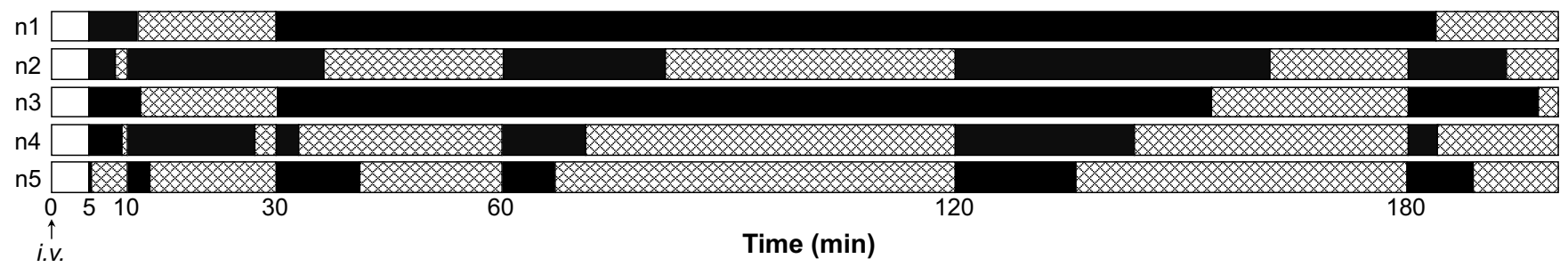

$\mathrm{n}=\mathbf{5}$, i.v. administration of PEG-haloperidol

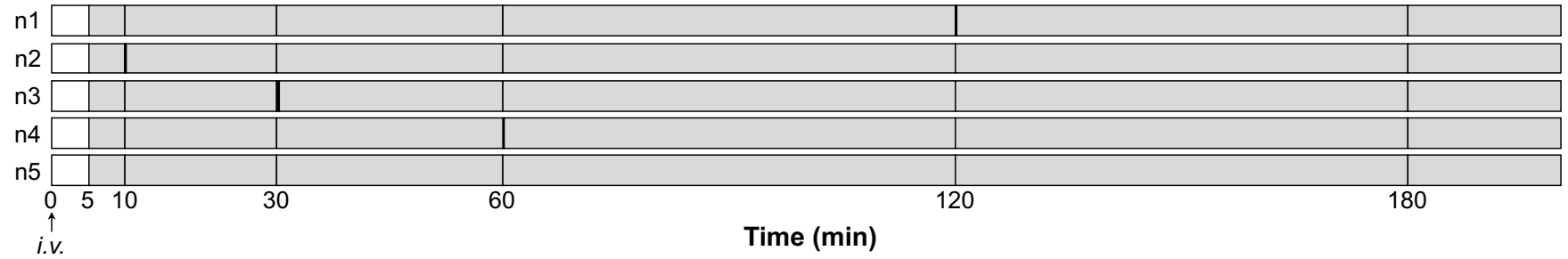

On the bar Abnormal behaviour $\square$ Normal behaviour

B)

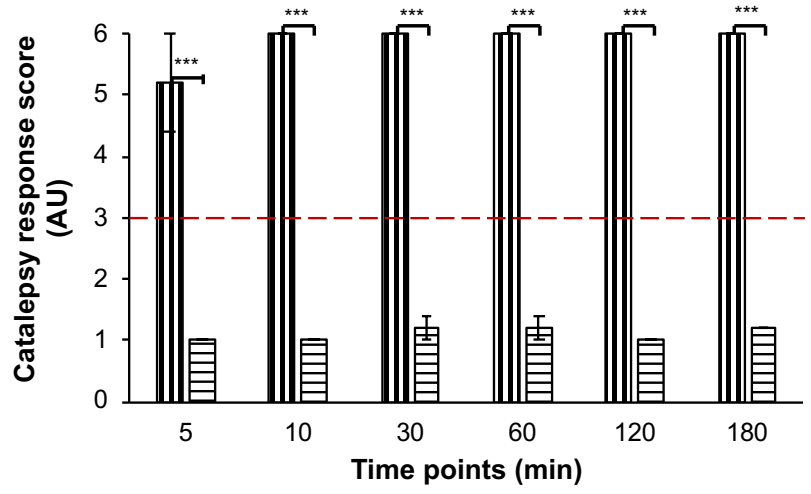

III Haloperidol
目 PEG-haloperidol

\begin{tabular}{|c|c|}
\hline $\begin{array}{l}\text { Catalepsy scc } \\
\text { Time on Bar }\end{array}$ & Score \\
\hline $0-10 \mathrm{~s}$ & 1 \\
\hline $11-20 s$ & 2 \\
\hline $21-30 \mathrm{~s}$ & 3 \\
\hline $31-40 \mathrm{~s}$ & 4 \\
\hline $41-50 \mathrm{~s}$ & 5 \\
\hline $51-60 \mathrm{~s}$ or mor & 6 \\
\hline
\end{tabular}

Fig. 6. In vivo catalepsy test in rats. Panel A, Time (min) recorded chart representing episodes of catalepsy induced after i.v. administration of free haloperidol and PEG-haloperidol; Panel B, Catalepsy response scores for free haloperidol and PEGhaloperidol and the scoring system used. The red dashed line represents the catalepsy cut off (Mean \pm SEM, n=5). n represents a single animal in the experiment.

Even when the rats fell from the bar, they exhibited abnormal behaviour characterised by reduced activity. All haloperidol treated animals achieved scores higher than the catalepsy cut-off score (i.e. >3) (Fig. B). Rats showed normal behaviour with no sign of catalepsy was recorded, with significant differences to haloperidol treated animals $(P<0.001)$ (Fig. A, 6B). The i.v. treatment of rats with free haloperidol led to episodes of catalepsy, consistent with antagonism of dopamine effects in the brain, in agreement with previous works [37-40]. However, when PEG-haloperidol was administered, the CNS-associated side effects of haloperidol on rats were absent. The normal behaviour seen in PEG-haloperidol treated animals is most likely related to the absence of haloperidol in the CNS. The lack of catalepsy observed following administration of the conjugate indirectly shows that haloperidol is not 
released from PEG in plasma. This is desirable and in line with our previously reported stability data [9]. Furthermore, PEG is well known to be biologically stable. Therefore, with respect to overall metabolism, it is likely that the conjugate will be excreted unmodified in the urine, following glomerular filtration, in line with other studies on PEG 6000 that report elimination (96\%), renally [41].

It is important to highlight that haloperidol and PEG-haloperidol were i.v. injected at a dose $\sim 13$ fold higher than the dose required to induce catalepsy in rats after s.c. injection [42]. As such, the lack of catalepsy observed after injection of the conjugate is most likely the result of the conjugate preventing haloperidol's permeability across the BBB, rather than the result of a loss of potency.

Hence, we demonstrate that the conjugation strategy used was capable of preventing the penetration of conjugated haloperidol through the BBB.

\section{Conclusions}

This study uses a PEG-haloperidol conjugate as a non-prodrug system to validate the hypothesis that conjugation to a polymer can localise a drug peripherally and avoid central effects. The approach relies on (a) polymer conjugation being effective at preventing BBB permeation and (b) the conjugated drug therapeutic activity being retained. In vivo studies in rats demonstrated strong evidence for (a), in that no unwanted cataleptogenic effects were observed when the rats were treated intravenously with PEG-haloperidol, in marked contrast to rats treated with haloperidol. With respect to (b), in vitro studies showed that PEGhaloperidol was biologically active as an antagonist of $\mathrm{D}_{2}$ receptors by inhibiting the dopamine-induced stimulation of $\left[{ }^{35} \mathrm{~S}\right] \mathrm{GTP} \gamma \mathrm{S}$-binding (although some loss of activity was observed). Molecular docking studies also confirmed that after conjugation, haloperidol preserved its ability to bind to $\mathrm{D}_{2}$ receptors, whilst also providing a possible explanation for the reduced activity of conjugated haloperidol compared to the free haloperidol. Taken together these findings suggest that PEGylation via a biologically stable linkage is a highly viable strategy to minimise penetration of a therapeutic drug through the BBB hence allowing drugs to be localised either within the CNS, or within the peripheral system, dependent on the point of administration. Future work will now look to interrogate this further, for example to realise the clinical applications of this work by probing the therapeutic activity of the conjugate for peripheral applications. 


\section{Acknowledgements}

The authors would like to thank the Council for At-Risk Academics (Cara) and the University of Reading for academic placement and financial support. The authors would like to thank Jessica Visconti for her preliminary contributions to the in silico permeability study. The authors would also like to thank the University of Reading for the provision of the Chemical Analysis Facility.

\section{References}

[1] J. Bicker, G. Alves, A. Fortuna, A. Falcão, Blood-brain barrier models and their relevance for a successful development of CNS drug delivery systems: A review, Eur. J. Pharm. Biopharm. 87 (2014) 409-432. doi:https://doi.org/10.1016/j.ejpb.2014.03.012.

[2] A. Talevi, Drug repositioning: current approaches and their implications in the precision medicine era, Expert Rev. Precis. Med. Drug Dev. 3 (2018) 49-61. doi:10.1080/23808993.2018.1424535.

[3] M.M. Patel, B.M. Patel, Crossing the Blood-Brain Barrier: Recent Advances in Drug Delivery to the Brain, CNS Drugs. 31 (2017) 109-133. doi:10.1007/s40263-016-0405-9.

[4] Y. Hu, D.E. Sieck, W.H. Hsu, Why are second-generation H1-antihistamines minimally sedating?, Eur. J. Pharmacol. 765 (2015) 100-106.

doi:https://doi.org/10.1016/j.ejphar.2015.08.016.

[5] A.A. Natfji, H.M.I. Osborn, F. Greco, Feasibility of polymer-drug conjugates for non-cancer applications, Curr. Opin. Colloid Interface Sci. 31 (2017) 51-66. doi:10.1016/J.COCIS.2017.07.004.

[6] B. Oller-Salvia, M. Sánchez-Navarro, E. Giralt, M. Teixidó, Blood-brain barrier shuttle peptides: an emerging paradigm for brain delivery, Chem. Soc. Rev. 45 (2016) 4690-4707. doi:10.1039/C6CS00076B.

[7] R. Satchi-Fainaro, M. Puder, J.W. Davies, H.T. Tran, D.A. Sampson, A.K. Greene, G. Corfas, J. Folkman, Targeting angiogenesis with a conjugate of HPMA copolymer and TNP-470, Nat Med. 10 (2004) 255-261. doi:10.1038/nm1002.

[8] K. Bui, D. Zhou, H. Xu, E. Floettmann, N. Al-Huniti, Clinical Pharmacokinetics and Pharmacodynamics of Naloxegol, a Peripherally Acting $\mu$-Opioid Receptor Antagonist, Clin. Pharmacokinet. (2016) 1-10. doi:10.1007/s40262-016-0479-z.

[9] F. Heath, A. Newman, C. Clementi, G. Pasut, H. Lin, G.J. Stephens, B.J. Whalley, H.M.I. Osborn, F. Greco, A novel PEG-haloperidol conjugate with a non-degradable linker shows the feasibility of using polymer-drug conjugates in a non-prodrug fashion, Polym. Chem. 7 (2016) 7204-7210. doi:10.1039/C6PY01418F. 
[10] X. Fu, Z.F. Song, C.Y. Fu, W.Q. Liang, A simple predictive model for blood-brain barrier penetration, Pharmazie. 60 (2005) 354-358.

[11] E. Kara, H. Lin, K. Svensson, A.M. Johansson, P.G. Strange, Analysis of the actions of the novel dopamine receptor-directed compounds (S)-OSU6162 and ACR16 at the D(2) dopamine receptor, Br. J. Pharmacol. 161 (2010) 1343-1350. doi:10.1111/j.1476-5381.2010.01010.x.

[12] O.H. Lowry, N.J. Rosebrough, A.L. Farr, R.J. Randall, PROTEIN MEASUREMENT WITH THE FOLIN PHENOL REAGENT, J. Biol. Chem. . 193 (1951) 265-275. http://www.jbc.org/content/193/1/265.short.

[13] A.N. Jain, Surflex: Fully Automatic Flexible Molecular Docking Using a Molecular Similarity-Based Search Engine, J. Med. Chem. 46 (2003) 499-511. doi:10.1021/jm020406h.

[14] S. Wang, T. Che, A. Levit, B.K. Shoichet, D. Wacker, B.L. Roth, Structure of the D2 dopamine receptor bound to the atypical antipsychotic drug risperidone, Nature. 555 (2018) 269. https://doi.org/10.1038/nature25758.

[15] Schrodinger LLC, Maestro, (2019).

[16] L. Grell, C. Parkin, L. Slatest, P.A. Craig, EZ-Viz, a tool for simplifying molecular viewing in PyMOL, Biochem. Mol. Biol. Educ. 34 (2006) 402-407. doi:10.1002/bmb.2006.494034062672.

[17] Schrodinger LLC, The PyMOL Molecular Graphics System, Version 1.8, (2015).

[18] J. Piazza, T. Hoare, L. Molinaro, K. Terpstra, J. Bhandari, P.R. Selvaganapathy, B. Gupta, R.K. Mishra, Haloperidol-loaded intranasally administered lectin functionalized poly(ethylene glycol)-block-poly(d,1)-lactic-co-glycolic acid (PEG-PLGA) nanoparticles for the treatment of schizophrenia, Eur. J. Pharm. Biopharm. 87 (5AD) 30-39. doi:10.1016/j.ejpb.2014.02.007.

[19] M. Wood, A. Ates, V.M. Andre, A. Michel, R. Barnaby, M. Gillard, In Vitro and In Vivo Identification of Novel Positive Allosteric Modulators of the Human Dopamine D2 and D3 Receptor., Mol. Pharmacol. 89 (2016) 303-312. doi:10.1124/mol.115.100172.

[20] T.P. Kenakin, The Schild regression in the process of receptor classification., Can. J. Physiol. Pharmacol. 60 (1982) 249-265.

[21] S. Kudo, T. Ishizaki, Pharmacokinetics of Haloperidol, Clin. Pharmacokinet. 37 (1999) 435456. doi:10.2165/00003088-199937060-00001.

[22] F.J. Rowell, S.M. Hui, A.F. Fairbairn, D. Eccleston, Total and free serum haloperidol levels in schizophrenic patients and the effect of age thioridazine and fatty acid on haloperidol-serum protein binding in vitro, Br. J. Clin. Pharmacol. 11 (1981) 377-382. doi:10.1111/j.13652125.1981.tb01135.x.

[23] S. Ulrich, S. Neuhof, V. Braun, F.P. Meyer, Therapeutic window of serum haloperidol concentration in acute schizophrenia and schizoaffective disorder., Pharmacopsychiatry. 31 (1998) 163-169. doi:10.1055/s-2007-979322.

[24] M.Y.S. Kalani, N. Vaidehi, S.E. Hall, R.J. Trabanino, P.L. Freddolino, M.A. Kalani, W.B. 
Floriano, V.W.T. Kam, W.A. Goddard, The predicted 3D structure of the human D2 dopamine receptor and the binding site and binding affinities for agonists and antagonists, Proc. Natl.

Acad. Sci. U. S. A. 101 (2004) 3815 LP - 3820. doi:10.1073/pnas.0400100101.

[25] Q. Wang, R.H. Mach, R.R. Luedtke, D.E. Reichert, Subtype Selectivity of Dopamine Receptor Ligands: Insights from Structure and Ligand-Based Methods, J. Chem. Inf. Model. 50 (2010) 1970-1985. doi:10.1021/ci1002747.

[26] R.R. Luedtke, Y. Mishra, Q. Wang, S.A. Griffin, C. Bell-Horner, M. Taylor, S. Vangveravong, G.H. Dillon, R.-Q. Huang, D.E. Reichert, R.H. Mach, Comparison of the Binding and Functional Properties of Two Structurally Different D2 Dopamine Receptor Subtype Selective Compounds, ACS Chem. Neurosci. 3 (2012) 1050-1062. doi:10.1021/cn300142q.

[27] T. Thomas, Y. Fang, E. Yuriev, D.K. Chalmers, Ligand Binding Pathways of Clozapine and Haloperidol in the Dopamine D2 and D3 Receptors, J. Chem. Inf. Model. 56 (2016) 308-321. doi:10.1021/acs.jcim.5b00457.

[28] L. Shi, J.A. Javitch, The Binding Site of Aminergic G Protein-Coupled Receptors: The Transmembrane Segments and Second Extracellular Loop, Annu. Rev. Pharmacol. Toxicol. 42 (2002) 437-467. doi:10.1146/annurev.pharmtox.42.091101.144224.

[29] K. Kristiansen, W.K. Kroeze, D.L. Willins, E.I. Gelber, J.E. Savage, R.A. Glennon, B.L. Roth, A Highly Conserved Aspartic Acid (Asp-155) Anchors the Terminal Amine Moiety of Tryptamines and Is Involved in Membrane Targeting of the 5-HT\&lt;sub\&gt;2A\&lt;/sub\&gt; Serotonin Receptor But Does Not Participate in Activation via a "Salt-Bridge Disruption," J. Pharmacol. Exp. Ther. 293 (2000) 735 LP - 746. http://jpet.aspetjournals.org/content/293/3/735.abstract.

[30] S. Vangveravong, Z. Zhang, M. Taylor, M. Bearden, J. Xu, J. Cui, W. Wang, R.R. Luedtke, R.H. Mach, Synthesis and characterization of selective dopamine D2 receptor ligands using aripiprazole as the lead compound, Bioorg. Med. Chem. 19 (2011) 3502-3511. doi:https://doi.org/10.1016/j.bmc.2011.04.021.

[31] A.C. Barton, H.C. Kang, M.S. Rinaudo, F.J. Monsma, R.M. Stewart-Fram, J.A. Macinko, R.P. Haugland, M.A. Ariano, D.R. Sibley, Multiple fluorescent ligands for dopamine receptors. I. Pharmacological characterization and receptor selectivity, Brain Res. 547 (1991) 199-207. doi:https://doi.org/10.1016/0006-8993(91)90963-V.

[32] M. Lyles-Eggleston, R. Altundas, J. Xia, D.M.N. Sikazwe, P. Fan, Q. Yang, S. Li, W. Zhang, X. Zhu, A.W. Schmidt, M. Vanase-Frawley, A. Shrihkande, A. Villalobos, R.F. Borne, S.Y. Ablordeppey, Design, Synthesis, and Evaluation of Metabolism-Based Analogues of Haloperidol Incapable of Forming MPP+-like Species, J. Med. Chem. 47 (2004) 497-508. doi:10.1021/jm0301033.

[33] D.M.N. Sikazwe, S. Li, L. Mardenborough, V. Cody, B.L. Roth, S.Y. Ablordeppey, Haloperidol: Towards further understanding of the structural contributions of its 
pharmacophoric elements at D2-like receptors, Bioorganic Med. Chem. Lett. 14 (2004) 57395742. doi:10.1016/j.bmcl.2004.09.046.

[34] K. Peprah, X.Y. Zhu, S.V.K. Eyunni, V. Setola, B.L. Roth, S.Y. Ablordeppey, Multi-receptor drug design: Haloperidol as a scaffold for the design and synthesis of atypical antipsychotic agents, Bioorg. Med. Chem. 20 (2012) 1291-1297.

doi:https://doi.org/10.1016/j.bmc.2011.12.019.

[35] M.S. LeDoux, Chapter 25 - Murine Models of Caytaxin Deficiency, in: M.S.B.T.-M.D. (Second E. LeDoux (Ed.), Academic Press, Boston, 2015: pp. 439-452. doi:https://doi.org/10.1016/B978-0-12-405195-9.00025-1.

[36] D.C. Hoffman, H. Donovan, Catalepsy as a rodent model for detecting antipsychotic drugs with extrapyramidal side effect liability., Psychopharmacology (Berl). 120 (1995) 128-133.

[37] T.J. Banasikowski, R.J. Beninger, Haloperidol conditioned catalepsy in rats: a possible role for D1-like receptors, Int. J. Neuropsychopharmacol. 15 (2012) 1525-1534. doi:10.1017/S1461145711001696.

[38] H.A. Jørgensen, O.A. Andreassen, K. Hole, The relationship between motor effects in rats following acute and chronic haloperidol treatment, Psychopharmacology (Berl). 116 (1994) 89-92. doi:10.1007/BF02244876.

[39] M. Li, Antipsychotic drugs on maternal behavior in rats, Behav. Pharmacol. 26 (2015) 616626. doi:10.1097/FBP.0000000000000168.

[40] P. Sachdev, C. Loneragan, F. Westbrook, Effect of prolonged treatment with haloperidol on "emotional" defecation and movement in rats in a well-habituated environment, Psychiatry Res. 54 (1994) 87-95. doi:https://doi.org/10.1016/0165-1781(94)90067-1.

[41] C. Su, Y. Liu, R. Li, W. Wu, J.P. Fawcett, J. Gu, Absorption, distribution, metabolism and excretion of the biomaterials used in Nanocarrier drug delivery systems, Adv. Drug Deliv. Rev. 143 (2019) 97-114. doi:https://doi.org/10.1016/j.addr.2019.06.008.

[42] S. Kapur, M.L. Wadenberg, G. Remington, Are animal studies of antipsychotics appropriately dosed? Lessons from the bedside to the bench., Can. J. Psychiatry. 45 (2000) 241-246. doi: $10.1177 / 070674370004500302$. 